\title{
LEGISLAÇÃO NA EDUCAÇÃO INCLUSIVA: ANALISANDO AS POLÍTICAS PÚBLICAS A PARTIR DE DADOS DO CENSO ESCOLAR
}

\author{
CLÁUDIA JUNQUEIRA MIRANDA* \\ CRISTINA MIYUKI HASHIZUME**
}

\begin{abstract}
RESUMO
O presente artigo objetiva refletir sobre a legislação e políticas públicas na educação inclusiva, relacionando-as à análise de dados do último censo escolar (2018) em relação à educação, no geral, e especificamente na educação inclusiva. Os resultados apontam que a legislação, apesar de garantidora dos últimos avanços sociais, ainda está muito longe de um patamar ótimo, em que a inclusão ocorra efetivamente.
\end{abstract}

Palavras-chave: Inclusão. Censo educacional. Direitos humanos.

\section{LEGISLATION IN INCLUSIVE EDUCATION: PUBLIC POLICIES ANALIZIS FROM SCHOOL CENSUS DATA}

\begin{abstract}
This article aims to discuss based on legislation and public policies in inclusive education, and associate them to the analysis of data from the latest school censuses (from 2000 to 2018) in relation to general education and specifically about inclusive education. The results show that the legislation, although ensure
\end{abstract}

* Mestre em Educação, pela Universidade Metodista de São Paulo, e professora de Educação Básica na rede privada da cidade de São Paulo.

** Professora do PPGE- UMESP. Dra. em Psicologia pelo Instituto de Psicologia da USP. 
the latest social advances, those are still far way from an excellent stage, that the inclusion occurs effectively.

Keywords: Inclusión. Educational census. Human rights.

\title{
LEGISLACIÓN EN EDUCACIÓN INCLUSIVA: ANÁLISIS DE POLÍTICAS PÚBLICAS DE LOS DATOS DEL CENSO ESCOLAR
}

\begin{abstract}
RESUMEN
Este artículo tiene como objetivo reflexionar sobre la legislación y las políticas públicas en educación inclusiva, relacionándolas con el análisis de datos de los últimos censos escolares (hasta 2018) en relación con la educación, en general, y específicamente en la educación inclusiva. Los resultados muestran que la legislación, a pesar de garantizar los últimos avances sociales, todavía está muy lejos de un nivel óptimo, en el que realmente se produce la inclusión.
\end{abstract}

Palabras clave: Inclusión. Censo educativo. Derechos humanos.

\section{INTRODUÇÃO}

Ao longo dos anos, a escola vem se modificando a fim de atender às novas demandas sociais. Dentre as inúmeras adaptações, está o atendimento ao aluno com deficiência na escola regular. Nesse sentido, surgem políticas públicas e leis para estabelecer e regulamentar o atendimento educacional inclusivo. Neste artigo nosso objetivo é refletir sobre a legislação e políticas públicas na educação inclusiva, relacionando-as à análise de dados dos últimos censos escolares em relação à educação, no geral, e especificamente na educação inclusiva.

\section{Políticas Públicas e inclusão}

As políticas são avaliadas com base na produção de indicadores, que demarcam algumas áreas prioritárias como, por exemplo, taxas de matrículas e escolarização, acesso à rede 
sanitária, calorias consumidas por dia, entre outros. Neste contexto, a criação da política fica submetida aos indicadores de avaliação, que são ditados por uma "política macroeconômica de minimização do papel do Estado na garantia dos direitos sociais" (ARELARO, 2017, p. 51).

Conforme a autora, a avaliação das políticas está vinculada ao público a que se destina, ainda que, teoricamente, ela deva ser para todos os brasileiros, já que a grande desigualdade social e a produção da política pública no contexto neoliberal acabam ditando ações que priorizam justamente os campos elencados nos indicadores. Assim, apenas um pequeno número de pessoas poderá usufruir de determinadas ações políticas.

Neste cenário, as pessoas com deficiência são caracterizadas como público-alvo das ações de políticas sociais. Segundo Arelaro (2017, p.52-53), há três motivos para tal: a) necessitam de ações que atendam suas deficiências - permanentes ou transitórias - em uma ou mais áreas, como, por exemplo, a educação e a saúde; b) é um grupo constituído, em sua maioria, de pessoas pobres; c) o paradigma médico e assistencial prevalece na elaboração das políticas destinadas para este público.

\section{MARCOS NORMATIVOS REFERENTES À EDUCAÇÃO ESPECIAL E INCLUSIVA NO BRASIL}

\section{Constituição Federal}

A Constituição Federal de 1988 trouxe significativos avanços relacionados à educação inclusiva ao colocar todas as pessoas em igualdade de condições, independente de origem, raça, sexo, cor, idade ou tipo de deficiência.

O artigo 205 estabelece a educação como direito de todos e dever do Estado e da família em colaboração com a sociedade, garantindo pleno desenvolvimento da pessoa, o exercício da cidadania e a qualificação para o trabalho. O inciso I do artigo 206 preconiza a igualdade de condições de acesso e a permanência na escola. 
O artigo 208 da CF representa um importante marco legal para o fortalecimento dos movimentos da educação inclusiva em nosso país, pois estabelece com a força da lei a obrigatoriedade do atendimento educacional especializado aos portadores de deficiência, preferencialmente na rede regular de ensino; entretanto, não é suficiente para dar subsídios ao trabalho do professor.

O artigo 209 da Constituição estabelece que a iniciativa privada responde aos mesmos critérios da educação pública em relação ao cumprimento das normas gerais da educação nacional e avaliação de qualidade pelo poder público.

\section{Declaração de Salamanca}

Em 1994 foi realizada a Conferência Mundial sobre Necessidades Educacionais Especiais, para tratar de princípios, políticas e práticas na área das necessidades especiais no que se refere à inclusão no sistema regular de ensino. A conferência foi realizada entre os dias 07 e 10 de junho daquele ano em Salamanca, na Espanha. Dessa conferência, destacam-se as seguintes resoluções: a de que a educação é direito de todos; que toda criança que possui dificuldade de aprendizagem pode ser considerada com necessidades educativas especiais, devendo estas terem acesso à escola regular; a escola deve adaptar-se às especificidades dos alunos - e não o contrário - e que o ensino deve ser diversificado e realizado num espaço comum a todos.

Podemos considerar que a Declaração de Salamanca representa o mais importante marco mundial na difusão da filosofia da educação inclusiva, ao promover orientações explícitas para que ações sejam desenvolvidas em âmbito regional, nacional e internacional. O documento fornece orientações referentes aos seguintes aspectos: política e organização; fatores relativos à escola; recrutamento e treinamento de professores; serviços externos de apoio; áreas prioritárias; perspectivas comunitárias; requerimentos relativos a recursos. 


\section{Lei de Diretrizes e Bases}

Em 20 de dezembro de 1996 foi sancionada a Lei no 9.394 para estabelecer as diretrizes e bases da educação nacional (LDB). Além de definir o conceito de educação, a lei visa a disciplinar a educação escolar e determinar que a educação esteja vinculada ao mundo do trabalho e à prática social.

A LDB trouxe fortalecimento para Educação Especial no Brasil, já que trata em capítulo específico o tema, além de orientações a respeito dos aspectos metodológicos e modalidades de ensino para a formação de professores da educação básica. Conforme o Art. 58,

Entende-se por educação especial, para os efeitos desta Lei, a modalidade de educação escolar oferecida preferencialmente na rede regular de ensino, para educandos com deficiência, transtornos globais do desenvolvimento e altas habilidades ou superdotação (BRASIL, LDB, 1996) (grifo nosso).

A LDB prevê a oferta de educação especial desde a educação infantil e estende-se ao longo da vida. O atendimento educacional deve ser realizado em classes, mas também será permitido em escolas e serviços especializados, sempre que não for possível a integração do aluno público-alvo da educação especial no ensino regular, em função das especificidades de cada educando.

O termo "preferencialmente" possibilita que as escolas continuem a encaminhar alunos com deficiência ou com dificuldade de aprendizagem para serviços especializados e apartados da escola regular. Assim como a inclusão, a exclusão escolar também está amparada pela lei.

De acordo com o artigo 59, desde que assegurados os padrões de qualidade, a educação escolar especial pode oferecer currículos, métodos, técnicas, recursos educativos e organização 
específicos para atender às necessidades dos alunos com deficiência, transtornos globais do desenvolvimento e altas habilidades ou superdotação. Assim, podemos afirmar que a lei é flexível no que diz respeito à adequação dos conteúdos escolares, métodos de ensino e avaliação para aqueles que possuem necessidades educativas especiais.

Consideramos que a LDB trouxe avanços ao situar a educação especial como uma modalidade de educação escolar e ao mencionar, explicitamente, educandos com deficiência, transtornos globais do desenvolvimento e altas habilidades ou superdotação, como público da educação especial. A lei também beneficia a inclusão escolar ao reiterar a preferência ao ensino regular para todos os alunos.

Reserva um capítulo específico sobre os profissionais da educação e enfatiza a necessidade de formação continuada e capacitação dos profissionais e também que a União, o DF, os estados e os municípios devem incentivar a formação de profissionais do magistério para atuar na educação básica pública, bem como promover a valorização e garantia dos estatutos e planos de carreira especificamente do magistério público. Não há, entretanto, menção às garantias ou valorização para professores das escolas particulares, abrindo precedente legal para que tais instituições atuem da maneira que for mais conveniente ou lucrativa.

No artigo 62 da LDB, reafirma-se o nível superior como o desejável, embora permita que profissionais formados no curso normal (nível médio) possam atuar na Educação Infantil e Ensino Fundamental I. Nesse cenário, os alunos e a sociedade perdem em qualidade, uma vez que a complexidade do trabalho do docente exigiria uma formação em nível superior.

Há de se destacar, entretanto, que o Plano Nacional de Educação tem como uma de suas metas (meta 15) que todos os professores da educação básica tenham formação específica de nível superior, obtida em curso de licenciatura na área de conhecimento em que atuam, até o ano de 2024. Entretanto, em 
rápida consulta ao site do PNE, observamos que apenas $\mathbf{5 0 . 6 \%}$ da meta 15 foram atingidas.

\section{RESOLUÇão CNE/CEB N No2/01 $^{\circ}$}

A Resolução CNE/CEB n ${ }^{\circ}$ 2, de 11 de setembro de 2001, institui as Diretrizes Nacionais para a Educação Especial na Educação Básica em todas as suas etapas e modalidades, de modo a atender aos alunos público-alvo da educação especial, ampliando o próprio conceito de educação especial e enfatizando a importância de se desenvolver as potencialidades dos alunos com necessidades educativas especiais:

Por educação especial, modalidade da educação escolar, entende-se um processo educacional definido por uma proposta pedagógica que assegure recursos e serviços educacionais especiais, organizados institucionalmente para apoiar, complementar, suplementar e, em alguns casos, substituir os serviços educacionais comuns, de modo a garantir a educação escolar e promover o desenvolvimento das potencialidades dos educandos que apresentam necessidades educacionais especiais, em todas as etapas e modalidades da educação básica (BRASIL, Resolução CNE/CEB 2/2001).

Conforme a Resolução, devem ser considerados educandos com necessidades educacionais especiais aqueles que apresentarem: dificuldades acentuadas de aprendizagem ou limitações no processo de desenvolvimento que possam dificultar o acompanhamento das atividades curriculares; dificuldade de comunicação e sinalização diferenciadas dos demais alunos; altas habilidades/ superdotação.

$\mathrm{O}$ Art. $7^{\circ}$ deste documento reitera que o atendimento aos alunos com necessidades educacionais especiais deve ser realizado em classes comuns da escola regular, bem como se organizar a fim de prover: a) professores das classes comuns e da educação 
especial capacitados e especializados; b) distribuição dos alunos com necessidades educacionais especiais pelas classes do ano escolar para que todos os alunos possam se beneficiar das diferenças; c) flexibilizações e adaptações curriculares, metodologias de ensino e recursos didáticos diferenciados; d) processos de avaliação adequados ao desenvolvimento dos alunos que apresentam necessidades educacionais especiais.

O documento também enfatiza a necessidade de serviços de apoio pedagógico especializado realizado na classe comum mediante, entre outros fatores, a disponibilização de apoios necessários à aprendizagem, à locomoção e à comunicação; e apoio pedagógico especializado em salas de recursos, nas quais o professor especializado em educação especial realize a complementação ou suplementação curricular, utilizando procedimentos, equipamentos e materiais específicos.

É permitido às escolas, de acordo com a Resolução, criar classes especiais para atendimento a alunos que apresentem dificuldades acentuadas de aprendizagem ou condições de comunicação diferenciadas. Entretanto, as classes especiais devem ser de caráter transitório e, a partir do desenvolvimento apresentado pelo aluno, a equipe pedagógica e a família devem decidir conjuntamente quanto ao seu retorno à classe comum.

\section{Plano Nacional de Educação em Direitos Humanos}

O Plano Nacional de Educação em Direitos Humanos (PNEDH), lançado em 2003, está apoiado em documentos internacionais e nacionais que concebem a educação como caminho para a cultura democrática, tolerância, solidariedade, justiça social, sustentabilidade, inclusão e pluralidade.

$\mathrm{Na}$ perspectiva do PNEDH, a educação é compreendida como um direito indispensável para o acesso a outros direitos. Portanto, a educação ganha ainda mais importância quando direcionada ao pleno desenvolvimento humano, valorizando o respeito aos grupos socialmente excluídos. Nessa perspectiva, a 
educação busca firmar a cidadania plena para a construção de conhecimentos, o desenvolvimento de valores, atitudes e comportamentos, além da defesa socioambiental e da justiça social.

Dentre os objetivos do PNEDH, está o incentivo para que pessoas com deficiência tenham acesso a ações de educação em direitos humanos, por meio da garantia da dignidade, igualdade de oportunidades, participação e autonomia, democratização do acesso, permanência e conclusão de todos na Educação Infantil, Ensino Fundamental e Médio, de modo a fomentar a consciência social crítica. Assim, "é necessário concentrar esforços, desde a infância, na formação de cidadãos(ãs), com atenção especial às pessoas e segmentos sociais historicamente excluídos e discriminados" (BRASIL, PNEDH, 2008, p. 17-18).

Quanto aos profissionais da educação, o PNEDH sugere a implementação de programas e projetos de formação e capacitação sobre educação em direitos humanos para gestores, professores e servidores, para que possam estar aptos a tratar das temáticas relativas a gênero, identidade de gênero, raça e etnia, religião, orientação sexual, pessoas com deficiências, entre outros.

\section{Política Nacional de Educação Especial na Perspectiva da EducaÇão InClusiva}

Durante muito tempo acreditou-se que a educação especial, oferecida em paralelo à educação comum, seria a forma mais apropriada para o atendimento aos alunos com deficiência ou que têm dificuldades em se adequar à rígida estrutura dos sistemas de ensino. Essa concepção resultou em práticas que enfatizavam aspectos relativos à deficiência do aluno, em contraposição a aspectos pedagógicos.

A Política Nacional de Educação Especial na Perspectiva da Educação Inclusiva é a ação política mais recente no campo da educação especial. Foi apresentada em 07 de janeiro de 2008 e determina que o papel da educação especial seja o de promover, de forma articulada ao ensino regular, o atendimento às 
necessidades educacionais especiais dos alunos que apresentam deficiência, transtornos globais do desenvolvimento, superdotação/altas habilidades.

Segundo a Política Nacional de Educação Especial na Perspectiva da Educação Inclusiva, é considerado aluno com deficiência aquele "que tem impedimentos de longo prazo, de natureza física, mental ou sensorial que, em interação com diversas barreiras, pode $[\mathrm{m}]$ ter restringida sua participação plena e efetiva na escola e na sociedade" (BRASIL, 2008, p. 15). Quanto aos estudantes com transtornos globais do desenvolvimento, são definidos como:

aqueles que apresentam alterações qualitativas das interações sociais recíprocas e na comunicação, um repertório de interesses e atividades restrito, estereotipado e repetitivo. Incluem-se nesse grupo estudantes com autismo, síndromes do espectro do autismo e psicose infantil (BRASIL, 2008, p. 15).

Já os alunos com altas habilidades/superdotação são definidos pela política como aqueles que:

demonstram potencial elevado em qualquer uma das seguintes áreas, isoladas ou combinadas: intelectual, acadêmica, liderança, psicomotricidade e artes, além de apresentar grande criatividade, envolvimento na aprendizagem e realização de tarefas em áreas de seu interesse (BRASIL, 2008, p. 15).

Além de definir e conceituar o público-alvo da educação especial, a Política Nacional de Educação Especial na Perspectiva da Educação Inclusiva também define o conceito de educação especial como sendo "uma modalidade de ensino que perpassa todos os níveis, etapas e modalidades, realiza o atendimento educacional especializado, disponibiliza os recursos e serviços 
e orienta quanto a (sic) sua utilização no processo de ensino e aprendizagem nas turmas comuns do ensino regular" (BRASIL, 2008, p. 16).

A Política Nacional de Educação Especial na Perspectiva da Educação Inclusiva também estabelece diretrizes no que diz respeito ao Atendimento Educacional Especializado (AEE), definindo como sua função "identificar, elaborar e organizar recursos pedagógicos e de acessibilidade que eliminem as barreiras para a plena participação dos estudantes, considerando suas necessidades específicas" (BRASIL, 2008, p. 16). É importante destacar que as atividades desenvolvidas no AEE são de caráter diferente daquelas realizadas na sala de aula comum, portanto não devem substituí-las. O AEE deve proporcionar atividades suplementares e/ou complementares à formação do aluno, visando sua autonomia e independência na e fora da escola.

De acordo com a Política, o AEE deve ser obrigatório em todas as etapas e modalidades da educação básica e realizado no contraturno - na própria escola ou no centro especializado -, de forma a apoiar o desenvolvimento dos estudantes. Além do Atendimento Educacional Especializado, também são assegurados ao aluno com deficiência um professor especialista e demais profissionais da educação para a inclusão e acessibilidade arquitetônica.

É comum que as escolas particulares de educação básica trabalhem com a oferta de ensino parcial ou ensino integral, cobrando valor proporcional ao tempo que o aluno permanece na instituição. O período integral não significa AEE, mas um período voltado à recreação e aulas extras dentro da própria escola, como robótica, inglês, balé, entre outros. A falta do Atendimento Especializado auxilia o trabalho do professor da sala regular, que, mesmo sem a formação adequada, acaba sendo o único responsável pelo desenvolvimento pedagógico do aluno com deficiência, às vezes com turmas cheias e apenas cinquenta minutos de aula, duas ou três vezes por semana. 
Com frequência, professores de escolas privadas afirmam que cabe a eles próprios descobrir como atender as necessidades dos alunos com deficiência, uma vez que em suas escolas não há oferta do Atendimento Educacional Especializado, contrariando o que preconiza a Política Nacional de Educação Especial na Perspectiva da Educação Inclusiva.

Esta Política enfatiza a formação do professor para o atendimento educacional especializado (professor especialista) - e a formação do professor regular (professor generalista). Tais profissionais devem estabelecer uma parceria, de forma a auxiliar o aluno no desenvolvimento de suas potencialidades, articulando o ensino comum ao atendimento especializado.

\section{Lei Brasileira de InClusão}

Em 06 de julho de 2015, foi sancionada a Lei $n^{\circ} 13.146$ (Lei Brasileira de Inclusão ou Estatuto da Pessoa com Deficiência), com o objetivo de assegurar e promover, em condições de igualdade, o exercício dos direitos e das liberdades fundamentais da pessoa com deficiência, visando à sua inclusão social e cidadania. É a lei mais recente e agrega uma série de discussões de vanguarda a respeito de políticas de inclusão, a partir de um viés progressista.

A LBI destina um capítulo à educação da pessoa com deficiência (capítulo IV), garantindo o direito à educação inclusiva em todos os níveis e modalidades escolares ao longo da vida, evitando toda forma de violência, negligência e discriminação, ao mesmo tempo em que incentiva talentos e habilidades, segundo suas características, interesses e necessidades de aprendizagem.

Conforme o artigo 28, é papel do poder público assegurar, criar, desenvolver, implementar, incentivar, acompanhar e avaliar os variados mecanismos educacionais existentes, de modo que os educandos com deficiência possam obter o melhor desenvolvimento de suas potencialidades por meio de: 
I - sistema educacional inclusivo em todos os níveis e modalidades, bem como o aprendizado ao longo de toda a vida;

II - aprimoramento dos sistemas educacionais, visando a garantir condições de acesso, permanência, participação e aprendizagem, por meio da oferta de serviços e de recursos de acessibilidade que eliminem as barreiras e promovam a inclusão plena;

III - projeto pedagógico que institucionalize o atendimento educacional especializado, assim como os demais serviços e adaptações razoáveis, para atender às características dos estudantes com deficiência e garantir o seu pleno acesso ao currículo em condições de igualdade, promovendo a conquista e o exercício de sua autonomia;

IV - oferta de educação bilíngue, em Libras como primeira língua e na modalidade escrita da língua portuguesa como segunda língua, em escolas e classes bilíngues e em escolas inclusivas;

$\mathrm{V}$ - adoção de medidas individualizadas e coletivas em ambientes que maximizem o desenvolvimento acadêmico e social dos estudantes com deficiência, favorecendo o acesso, a permanência, a participação e a aprendizagem em instituições de ensino;

VI - pesquisas voltadas para o desenvolvimento de novos métodos e técnicas pedagógicas, de materiais didáticos, de equipamentos e de recursos de tecnologia assistiva;

VII - planejamento de estudo de caso, de elaboração de plano de atendimento educacional especializado, de organização de recursos e serviços de acessibilidade e de disponibilização e usabilidade pedagógica de recursos de tecnologia assistiva;

VIII - participação dos estudantes com deficiência e de suas famílias nas diversas instâncias de atuação da comunidade escolar; 
IX - adoção de medidas de apoio que favoreçam o desenvolvimento dos aspectos linguísticos, culturais, vocacionais e profissionais, levando-se em conta o talento, a criatividade, as habilidades e os interesses do estudante com deficiência; $\mathrm{X}$ - adoção de práticas pedagógicas inclusivas pelos programas de formação inicial e continuada de professores e oferta de formação continuada para o atendimento educacional especializado;

XI - formação e disponibilização de professores para o atendimento educacional especializado, de tradutores e intérpretes de Libras, de guias intérpretes e de profissionais de apoio;

XII - oferta de ensino da Libras, do Sistema Braille e de uso de recursos de tecnologia assistiva, de forma a ampliar habilidades funcionais dos estudantes, promovendo sua autonomia e participação;

XIII - acesso à educação superior e à educação profissional e tecnológica em igualdade de oportunidades e condições com as demais pessoas;

XIV - inclusão em conteúdos curriculares, em cursos de nível superior e de educação profissional técnica e tecnológica, de temas relacionados à pessoa com deficiência nos respectivos campos de conhecimento;

XV - acesso da pessoa com deficiência, em igualdade de condições, a jogos e a atividades recreativas, esportivas e de lazer, no sistema escolar;

XVI - acessibilidade para todos os estudantes, trabalhadores da educação e demais integrantes da comunidade escolar às edificações, aos ambientes e às atividades concernentes a todas as modalidades, etapas e níveis de ensino;

XVII - oferta de profissionais de apoio escolar; XVIII - articulação intersetorial na implementação de políticas públicas (BRASIL. Lei Brasileira de Inclusão, 2015). 
A Lei Brasileira de Inclusão se aplica igualmente a instituições de ensino públicas e privadas, de qualquer nível e modalidade de ensino, sendo vedada a cobrança de valores adicionais de qualquer natureza em suas mensalidades, anuidades e matrículas no cumprimento dessas determinações. Com exceção para os incisos IV (oferta de educação bilíngue, em Libras como primeira língua e na modalidade escrita da língua portuguesa como segunda língua) e VI (pesquisas voltadas para o desenvolvimento de novos métodos e técnicas pedagógicas, de materiais didáticos, de equipamentos e de recursos de tecnologia assistiva), todas as demais determinações devem ser seguidas pelas escolas particulares.

É importante ressaltar que a LBI desobriga as instituições educacionais privadas a ofertarem, sem custo, educação em Libras, mas enfatiza que as escolas não podem se recusar a matricular alunos com deficiência. Tal contradição, na prática, permite que o aluno esteja na escola, mas impede que ele participe dela. Outro aspecto a se considerar é o fato de isentar (desobrigar) as escolas privadas de incentivar pesquisas para o desenvolvimento pedagógico. Nesse cenário, perdem os alunos com deficiência e também o professor, que fica impedido de se aprimorar por falta de incentivos por parte da instituição escolar.

No primeiro capítulo da LBI, que trata das disposições gerais, encontramos as definições para os profissionais que atuam junto às pessoas com deficiência:

XII - atendente pessoal: pessoa, membro ou não da família, que, com ou sem remuneração, assiste ou presta cuidados básicos e essenciais à pessoa com deficiência no exercício de suas atividades diárias, excluídas as técnicas ou os procedimentos identificados com profissões legalmente estabelecidas;

XIII - profissional de apoio escolar: pessoa que exerce atividades de alimentação, higiene e locomoção do 
estudante com deficiência e atua em todas as atividades escolares nas quais se fizer necessária, em todos os níveis e modalidades de ensino, em instituições públicas e privadas, excluídas as técnicas ou os procedimentos identificados com profissões legalmente estabelecidas; XIV - acompanhante: aquele que acompanha a pessoa com deficiência, podendo ou não desempenhar as funções de atendente pessoal (BRASIL. Lei Brasileira de Inclusão, 2015 - grifo nosso).

Em que pese a legislação que regulamenta as atribuições do AEE e do direito à educação universal pelos alunos com deficiências, algumas escolas particulares, a partir da lógica mercantilista, muitas vezes não oferecem um profissional para dar suporte aos alunos com deficiência, deixando esta responsabilidade para o professor da sala regular que, devido às especificidades do Ensino Fundamental II (apenas cinquenta minutos por aula) dificilmente consegue dar atenção ao aluno com necessidades educacionais específicas.

Esta realidade vem dificultando o trabalho do professor do Ensino Fundamental II por alguns motivos: a) salas cheias; b) tempo reduzido e insuficiente para realizar todas as tarefas necessárias (chamada, correções, explicações); c) indisciplina dos alunos. Em se tratando de turmas de $6^{\circ}$ ano, há ainda o agravante de ser um ano de transição do Ensino Fundamental I para o Ensino Fundamental II, implicando mudança de carga horária, troca de um único professor regente (polivalente) para vários professores especialistas, início da adolescência.

Análise sobre o censo demográfico no que tange à educação inclusiva (1991 a 2018).

A partir do Censo Escolar do INEP (2018) analisamos os dados sobre a incidência de alunos matriculados que se autodeclararam com deficiência para, em posse deles, realizarmos análises sobre o direito à educação. Percebemos que, em que 
pese haver uma vasta legislação que regulamenta o ensino a alunos com deficiência, bem discutido nos tópicos anteriores, ainda assim tal legislação se mostra insuficiente na realidade educacional do país.

A partir dos censos demográficos do IBGE de 1991, 2000 e 2010 constatou-se, respectivamente, $1,14 \%, 14,48 \%$ e $23 \%$ da população têm algum tipo de deficiência em nosso país. Conforme Arelaro (2017), a discrepante variação nas porcentagens se deve à própria definição da deficiência e, consequentemente, à forma de identificá-la. O IBGE, nas avaliações de 2000 e 2010, utilizou a autodeclaração da pessoa sobre sua deficiência. Entendemos, a partir daí, que os movimentos sociais de apoio à inclusão, não apenas escolar, mas também social influenciaram a autopercepção dos participantes do censo, que, ao terem uma visão mais real de si e de seus direitos, se autoidentificaram como pessoas com deficiência, o que enriqueceu o levantamento realizado.

Na visão de Arelaro (2017), na área da educação os indicadores apresentam dados sobre o perfil de atendimentos prestados para as pessoas com deficiência, mas não necessariamente sobre a escolarização.

O Censo Escolar do INEP (2018) apresenta indicadores de matrículas e rendimento dos alunos de nosso país. Para nossa pesquisa documental, filtramos os dados para que pudéssemos observar as informações referentes à inclusão no país como um todo e também no estado e na cidade de São Paulo, conforme quadro a seguir.

O número de matrículas da educação especial chegou a 1,2 milhão em 2018, um aumento de 33,2\% em relação a 2014. Esse crescimento foi influenciado pelas matrículas de ensino médio, que dobraram em quantidade durante o período. Considerando apenas os alunos de 4 a 17 anos da educação especial, verifica-se que o percentual de matrículas de alunos incluídos em classe comum também vem aumentando gradativamente, passando de $87,1 \%$ em 2014 para 92,1\% em 2018. 


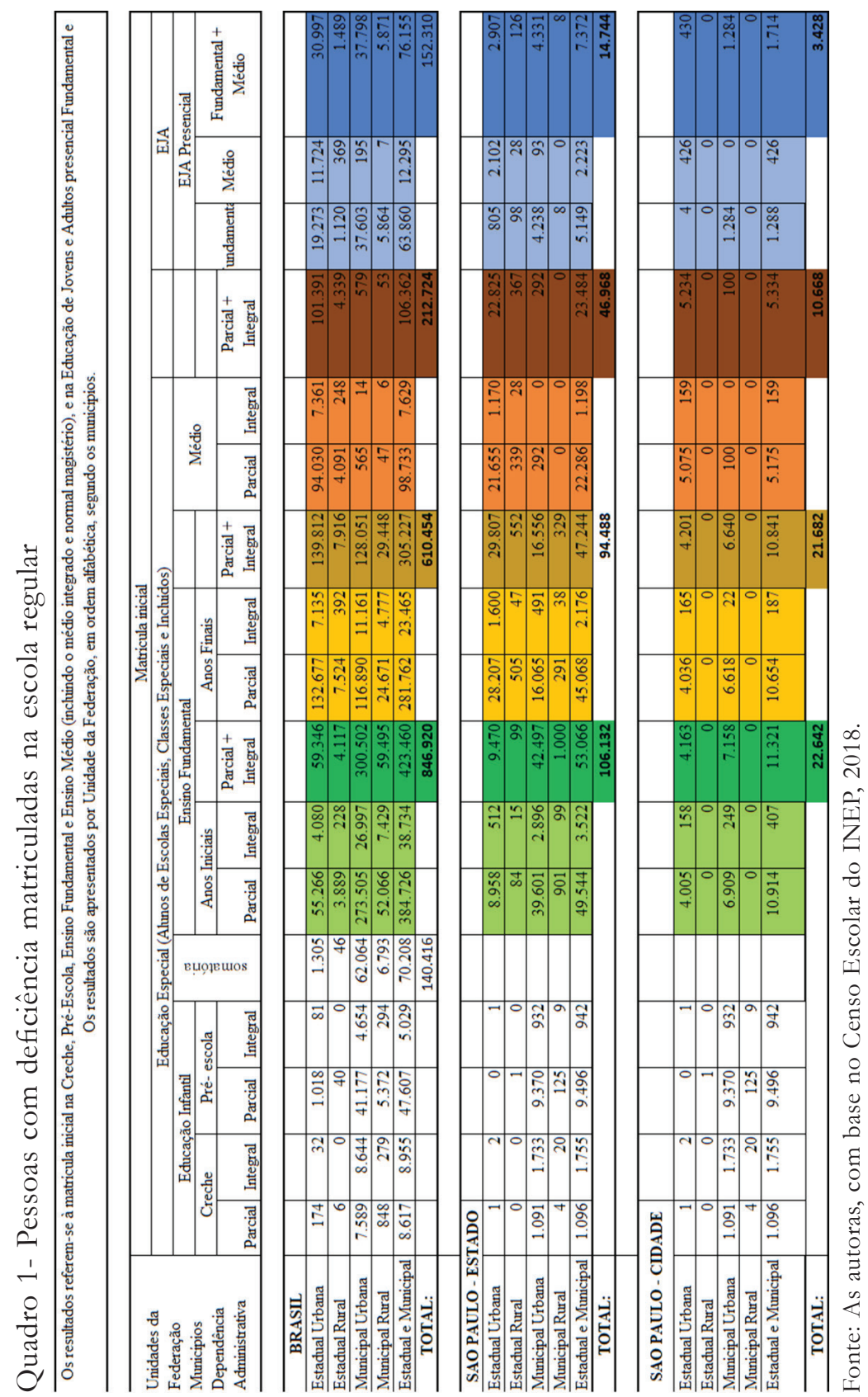

36 Cadernos de Educação, v.19, n. 38, jan.-jun. 2020 
Apesar de dados tão favoráveis, percebemos informações preocupantes no que se referem à permanência desses alunos na continuidade de seus estudos ao longo das séries e níveis escolares.

Como também podemos observar no quadro, no estado de São Paulo o número de matrículas das pessoas com deficiência nas escolas regulares diminui significativamente na passagem do Ensino Fundamental I - anos iniciais - para o Ensino Fundamental II - anos finais, diminuindo de 106.132 para 94.488 (colunas verde escuro e ocre, respectivamente). Mas a diminuição é ainda mais acentuada na passagem do Ensino Fundamental II para o Ensino Médio, saindo de 94.488 alunos para 46.968, ou seja, praticamente metade dos alunos que fizeram o Ensino Fundamental II não se matricula no Ensino Médio. A mesma situação acontece na cidade de São Paulo, que apresenta uma queda de mais de 50\% no índice de matrículas para o Ensino Médio, em relação ao Ensino Fundamental II, caindo de 21.682 matrículas para 10.668 .

É importante ressaltar que, em nosso país, educação básica é obrigatória e gratuita dos 4 (quatro) aos 17 (dezessete) anos de idade, ou seja, para a faixa etária que mostramos em nosso quadro. A evasão escolar das pessoas com deficiência nos permite refletir sobre o tipo de educação oferecida para este público que, apesar das inúmeras ações políticas, continua fora do processo de escolarização.

O Censo Escolar (2018) apresenta poucas informações acerca da educação especial nas escolas privadas, limitando-se a destacar apenas que o percentual de matrículas vem subindo desde 2014 em todas as dependências administrativas (Federal, Estadual, Municipal e Privada). Outras nuances, por exemplo, relativas à permanência, formação de professores, efetividade do plano AEE, preconizado em 2008, no Política Nacional de Educação Especial na Perspectiva da Educação Inclusiva não são levantadas nessas estatísticas. 
Figura 1- Alunos com deficiência por dependência administrativa

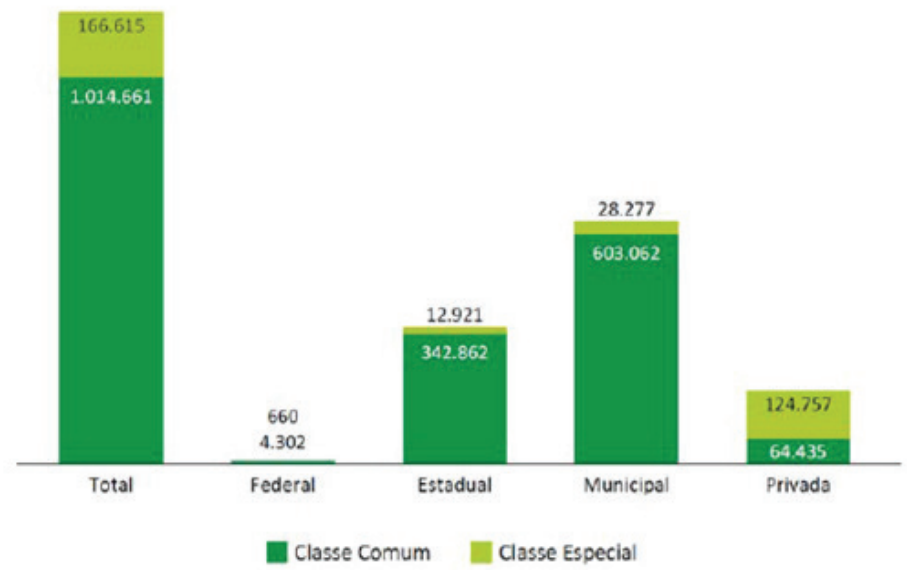

Fonte: Censo da Educação Básica do Instituto Nacional de Estudos e Pesquisas Educacionais Anísio Teixeira, 2018.

Conforme a Figura 1, do total de 1,2 milhão de alunos com deficiência matriculados nas escolas brasileiras, aproximadamente 15\% (190.000) estão em instituições particulares, o que demonstra, mais uma vez, a educação inclusiva concentrada nas mãos do estado. Discutimos com mais especificidade as diferenças entre educação inclusiva em escolas privadas e públicas (MIRANDA, 2020). Por definição, a escola pública deve, além de servir o público, atuar apenas dentro do que está na lei. Portanto, tem por obrigação garantir que a educação seja acolhedora e afirmadora de direitos, conforme preconiza a lei, o que, apesar das várias dificuldades da aplicabilidade da legislação, ainda se mostra como local que fundamentalmente acolhe, na prática, os alunos com deficiência.

Apesar de a lei tornar obrigatório o aceite da matrícula de crianças com deficiência, os setores público e privado lidam diferentemente com as solicitações de pais no que tange ao cumprimento do que está na lei. Isso se refere não apenas às matrículas, mas também ao apoio especializado, em contraturno 
a que o aluno deve ter direito, mas igualmente em relação às atividades de apoio escolar e metodologias didáticas alternativas que precisam ser readequadas às especificidades do aluno com deficiência. Ainda, se somam a essas questões, o trabalho pedagógico da escola, que deve formar para o respeito à alteridade.

Do total de alunos, apenas 34\% (64.435) estão incluídos em sala regular (INEP, Resumo Técnico Censo da Educação Básica 2018. p. 37). O que mostra que ainda temos que caminhar muito no que se refere à educação inclusiva, e não integrativa. Não basta colocarmos os alunos com deficiência fisicamente nas escolas, o que é conhecido como integração escolar, mas devemos mudar a cultura institucional e cidadã de toda comunidade escolar, reconhecendo a importância da construção de uma nova geração de alunos-cidadãos que dialoguem com a alteridade e as políticas sociais que afirmem seu reconhecimento.

As informações apresentadas, ainda que insuficientes, nos permitem verificar que a inclusão ainda não ocorre integralmente nas escolas, tanto nas públicas quanto nas privadas, uma vez que, na maior parte das vezes, alunos com deficiências continuam recebendo serviços educacionais em classes separadas.

O Plano Nacional de Educação em Direitos Humanos entende a educação como um instrumento de criação e promoção de uma cultura universalista dos direitos humanos, pensando no fortalecimento do respeito aos direitos e liberdades fundamentais do ser humano. Tal máxima deve ser cumprida principalmente no que se refere ao aluno com deficiência. O PNEDH, assim como a LBI, mostram que não se trata apenas de uma transmissão de conhecimentos que deve ser extensiva a esses alunos, mas que uma mudança na mentalidade social deve ser construída. Daí concluímos a importância da Educação e Direitos Humanos.

Algumas considerações para não concluir...

Em que pese a existência de tantas leis que referendam ações junto a movimentos de inclusão, percebemos ainda a 
ausência de políticas, aliada a perdas de direitos (em todos os sentidos) no Brasil. E é por via dessa destituição e erosão dos direitos e das esferas de representação, que se ergue um falso consenso, propalado pelas redes sociais e grande mídia, de que a meritocracia e as leis do mercado são exclusivos princípios estruturadores da sociedade e da política, e que diante desses imperativos, não há nada a fazer.

Uma esmorecimento do caráter político dos direitos faz o senso comum pender para a visão privatista de educação, recusando a alteridade, ao mesmo tempo em que obstruia dimensão ética da vida social por via da recusa dos princípios da responsabilidade pública e obrigação social. Para além do discurso ideológico e parcial, percebemos um movimento social no Brasil que engendra uma sociedade dividida internamente e fraturada por suas contradições e antinomias. Essas contradições são necessárias e inerentes a outras contradições sociais, que afetam diretamente a discussão em relação à alteridade.

É importante, sim, mapear as políticas, leis, regulamentos, histórias de vida, testemunhos, estatísticas, etc., mas tal levantamento se mostra insuficiente quando propomo-nos a resgatar essa consciência perdida, dominada e discriminada, por meio do entendimento de que o presente é uma consequência da história de sucessivos processos de exploração de classes e sujeitos, imbuídos de uma consciência histórica.

Quando falamos de inclusão, mais correto seria utilizarmos o binômio inclusão-exclusão, pois nenhum grupo se enquadra apenas em situação de inclusão OU de exclusão. Nesse complexo processo dinâmico, ora os papéis se invertem, ora se transferem de modo que um mesmo sujeito possa ser classificado duplamente em incluído ou excluído. Ao utilizarmos a expressão referida, transferimos à terminologia uma complexidade sobre a realidade que se analisa (LOPES, 2017).

A inclusão não pode se amparar em soluções salvacionistas, como ações de voluntariado ou doações. Mesmo as leis que, 
apesar de serem fundamentais para a construção de políticas públicas e ações afirmativas, não são suficientes. Trata-se de pensarmos para além de ações particulares de inclusão, amplificando a discussão para uma cobrança pelo comportamento e aprendizado médio, como forma de governar a população. A universalização e o gozo dos direitos passam por análises desde as relações na sala de aula até práticas e políticas educacionais (de formação de professores, plano de carreira, inclusão).

É evidente, em nossas análises, o anseio pela governamentalidade sobre os corpos e desejos dessas crianças e famílias do processo inclusivo. Atuar e prescrever sobre o comportamento delas e seus possíveis transtornos é manter o controle e a legitimidade de um saber especializado (seja da Medicina, da Inclusão ou da indústria farmacêutica) como controle da subjetividade e do simbolismo que subjaz a normatização social. A formação de professores face a essas questões deve problematizar os preconceitos e estigmas que se atrelam aos diagnósticos e sobre a deficiência em sim. Ao discutir a inclusão, percebe-se uma visão medicalizada sobre o aluno diferente: diagnósticos, laudos causam o borramento da condição subjetiva desse aluno, já que tomamos a parte (o aluno) pelo todo (a deficiência). Além disso, quando admitimos que uma criança é diferente, hierarquizam-se modos corretos de existência, modelos normais padronizados e velocidades médias na aprendizagem ou nos modos de aprender.

Podemos pensar por que incomoda tanto a diferença, as formas fora do padrão, a possibilidade de fugir no normal? Devemos refletir por que é tão importante o desejo de se controlar os corpos, os comportamentos, as aparências, os gestos? Para além do discurso da vitimização, sabemos que hoje nos deparamos com "sujeitos falantes", cientes de seus direitos e deveres e que trazem dilemas atuais que se tornam específicos e que se singularizam, em torno de feixes diferenciados, com plataformas diferenciadas. Frente a esse público, se inserem as pessoas com deficiências, que, apesar de vários avanços no que 
se refere à legislação, ainda patinamos no lidar cotidianamente com as precariedades da vida escolar, que ora se impõem como segregadoras, ora como transgressoras.

Trata-se, por fim, de uma questão de Direitos Humanos, tendo em vista que tanto o tratamento digno quanto o acesso livre à educação são cerceados com práticas que impedem uma relação igualitária e respeitosa no que se refere ao aluno com deficiência (HASHIZUME, 2020).

Acreditamos ser importante recuperar o protagonismo e revitalização de discursos e práticas garantidores dos direitos adormecidos, extrapolando a visão alienada e intolerante, que, infelizmente, estamos vendo recrudescer nos tempos atuais.

\section{REFERÊNCIAS}

ARElARO, L. R. G.; SILVA, S. (Org.). Direitos Sociais, Diversidade e Exclusão: A sensibilidade de quem as vive. Campinas, SP: Mercado de Letras, 2017.

BRASIL, 2015, Lei n ${ }^{\circ}$ 13.146, de 6 de julho de 2015. Lei Brasileira de Inclusão da Pessoa com Deficiência. Disponível em: http://www.planalto.gov. br/ccivil_03/_Ato2015-2018/2015/Lei/L13146.htm. Acesso em 28/11/2018. BRASIL, Lei no 9.394, de 20 de dezembro de 1996. Diretrizes e Bases da Educação Nacional. Brasília, DF, Senado, 1996.

BRASIL. Comitê Nacional de Educação em Direitos Humanos. Plano Nacional de Educação em Direitos Humanos: 2007. Brasília: Secretaria Especial dos Direitos Humanos, Ministério da Educação, Ministério da Justiça, UNESCO, 2007.

BRASIL. Conselho Nacional de Educação. Resolução no 1 de 18 de fevereiro de 2002. Formação de Professores da Educação Básica em nível superior. Diário Oficial [da] República Federativa do Brasil. Brasília: MEC/SEESP, 2000. BRASIL. Conselho Nacional de Educação. Resolução no 1 de 18 de fevereiro de 2002. Formação de Professores da Educação Básica em nível superior. Diário Oficial [da] República Federativa do Brasil. Brasília: MEC/SEESP, 2002. BRASIL. Conselho Nacional de Educação. Resolução no 2 de 11 de setembro de 2001. Diretrizes Nacionais para a Educação Especial na Educação Básica. Diário Oficial da República Federativa do Brasil. Brasília: MEC/ SEESP, 2001.

BRASIL. Constituição da República Federativa do Brasil: promulgada em 05 de outubro de 1998. Brasília, DF: Senado Federal, 1988. 
BRASIL. Lei no 13005, de 25 de junho de 2014. Aprova o Plano Nacional de Educação - PNE. Diário Oficial [da] República Federativa do Brasil. Brasília: Congresso Nacional. 2014.

BRASIL. Ministério da Educação. Decreto no 6755, de 29 de janeiro de 2009. Dispõe sobre a Política Nacional de Formação de Profissionais do Magistério da Educação Básica. Brasília, DF, 2009.

BRASIL. Política Nacional de Educação Especial na Perspectiva da Educação Inclusiva. Brasília: MEC. SEESP. Disponível em www.mec.gov. br. Acesso em 05/08/2019.

DECLARAÇÃO DE SALAMANCA: Sobre Princípios, Políticas e Práticas na Área das Necessidades Educativas Especiais, 1994, Salamanca-Espanha. Disponível em: http://portal.mec.gov.br/seesp/arquivos/pdf/salamanca.pdf Acesso em: 05/09/2019

DELIBERAÇÃO CEE N ${ }^{\circ}$ 10/97. Normas para elaboração do Regimento dos Estabelecimentos de Ensino Fundamental e Médio. Disponível em https://www.sieeesp.org.br/ Acesso em 18/12/2019

DORNAS, R. Escolas particulares debatem quem deve arcar com custos da inclusão. Jornal Nacional: 26 nov. 2015. Entrevista concedida à Sandra Passarinho

HASHIZUME, C.M. Inclusão e Direitos Humanos: refletindo sobre o tema a partir da formação de professores. CONTEMPORÂNEOS. Ed. 20. Junho, 2020.

INDICAÇÃO CEE N¹3/97. Diretrizes para elaboração de Regimento das Escolas do Estado de São Paulo. Disponível em: http://siau.edunet. sp.gov.br/ItemLise/arquivos/notas/indcee13_97.htm Acesso em 18/12/2019 INSTITUTO NACIONAL DE ESTUDOS E PESQUISAS EDUCACIONAIS ANÍSIO TEIXEIRA (INEP). Censo Escolar, 2018. Brasília: MEC, 2019.

LOPES, M.C.; FABBRIS, E.H. Inclusão \& Educação. Belo Horizonte: Autêntica, 2017

MIRANDA, C. J. Inclusão na escola privada: desafios do professor de Ensino Fundamental II na cidade de São Paulo. 2020. Dissertação (Mestrado em Educação) - Universidade Metodista de São Paulo, São Bernardo do Campo, 2020. 